Article

\title{
Effects of the Chiral Fungicides Metalaxyl and Metalaxyl-M on the Earthworm Eisenia fetida as Determined by ${ }^{1} \mathrm{H}$-NMR-Based Untargeted Metabolomics
}

\author{
Renke Zhang and Zhiqiang Zhou * \\ Beijing Advanced Innovation Center for Food Nutrition and Human Health, Department of Applied Chemistry, \\ China Agricultural University, Beijing 100193, China; zhang_ink@cau.edu.cn \\ * Correspondence: zqzhou@cau.edu.cn; Tel.: +86-10-62733089
}

Received: 3 March 2019; Accepted: 30 March 2019; Published: 2 April 2019

check for updates

\begin{abstract}
Although metalaxyl and metalaxyl-M are widely used fungicides, very little is known about their subacute and enantiospecific effects on the earthworm metabolome. In this study, Eisenia fetida were exposed to metalaxyl and metalaxyl-M at three concentrations $(0.5,5$ and $50 \mathrm{mg} / \mathrm{kg}$ ) for seven days. ${ }^{1} \mathrm{H}$ nuclear magnetic resonance $\left({ }^{1} \mathrm{H}-\mathrm{NMR}\right)$-based untargeted metabolomics showed that metalaxyl and metalaxyl-M exposure disturbed earthworms' metabolism at all three concentrations. Endogenous metabolites, such as succinate, arginine, aspartate, urea, asparagine, alanine, trimethylamine, taurine, cysteine, serine, threonine, histidine, lysine, glucose, choline, carnitine, citric acid, alpha-ketoisovaleric acid, fumaric acid and so on, were significantly changed. These results indicate that metalaxyl and metalaxyl-M produce different, enantiospecific disturbances in the earthworm metabolism, particularly in the tricarboxylic acid (TCA) and urea cycles. The application of untargeted metabolomics thus provides more information for evaluating the toxic risks of metalaxyl and metalaxyl-M.
\end{abstract}

Keywords: metabolomics; metalaxyl; earthworm; enantiospecific effects

\section{Introduction}

Metalaxyl and metalaxyl-M are the world's most widely used acetylalanine fungicides; they inhibit the synthesis of ribosomal RNA in mycelium. Metalaxyl proper is a racemic mixture [1], while metalaxyl-M is solely (97\%) the R-enantiomer [2]. Some studies indicate that the two enantiomers have different effects on the metabolomes of rats [3,4] and human cells [5]. Toxicological evaluations on earthworms found LC50 values for metalaxyl and metalaxyl-M of 0.022 and $0.052 \mathrm{mg} \mathrm{cm}^{-2}$, respectively [1], but the underlying mechanism of this toxicity and the lower toxicity of the R-enantiomer is not well understood.

This is a potentially important issue because nearly $80 \%$ of the soil animal biomass consists of earthworms, which are key members of the soil ecosystem because of their important role in soil development and maintenance [6]. Earthworms can serve as model organisms to detect soil contamination because they readily ingest pollutants or absorb them through their skin $[7,8]$. A major goal of ecotoxicology studies is thus to determine the impact of exposure on the behavior, reproduction, growth, and survival of the earthworms. Unfortunately, such studies are sometimes limited in the scope of the pollutant concentrations studied, even though in practice the range of relevant concentrations can be quite wide, due to processes such as pesticide runoff into non-agricultural areas [9]. It is still a challenge to determine the effects of pollutants on target organisms such as earthworms at the low concentrations that can be encountered in the field. 
Metabolomics is potentially a powerful tool to accomplish this purpose; it has been used to elucidate the toxic effects of such substances as metals [10], nanoparticles [11], and pharmaceuticals [12]. In particular, metabolomic studies using ${ }^{1} \mathrm{H}$ nuclear magnetic resonance (NMR) have proven effective in evaluating the response of organisms to pesticide exposure [13-20], and have become a widely used tool for the study of the effects of soil contaminants on earthworms [21-25]. This method is fast and can determine quantitative changes in the levels of metabolites, such as amino acids and sugars, provoked by an external stressor [26-30]. Being an untargeted technique, such an analysis can be reproduced accurately across different laboratories [31-36], providing insights into the reaction of the organism to an external source of stress, its molecular endpoints in terms of changes in metabolite levels, and in depicting the mode of toxicity of the contaminants [37].

The earthworm Eisenia fetida was exposed to metalaxyl and metalaxyl-M at three different concentrations for seven days in artificial soil, in order to determine the metabolomic impact of these two fungicides. The concentrations used were $0.5,5$, and $50 \mathrm{mg} / \mathrm{kg}$; these were chosen based on the concentration of fungicide applied in the field and the maximum residue limit (MRL). The main objective was to observe changes in metabolites provoked by metalaxyl and metalaxyl-M exposure, and to evaluate the potential mode of action of metalaxyl and metalaxyl-M in earthworms. Principal component analysis (PCA) was used to provide a quick overview of shifts in metabolites among different earthworm groups. Partial least squares-discriminant analysis (PLS-DA) was then applied for a deeper analysis of the metabolomic data.

\section{Results and Discussion}

\subsection{Earthworm Body Weight}

The control $(0.22 \pm 0.05 \mathrm{~g})$ and treated groups $(0.20 \pm 0.03 \mathrm{~g})$ average body weights did not significantly change after 7 days of exposure at all three concentrations tested (Figure S1). No obvious injury or toxic symptoms were observed.

\subsection{H NMR Spectroscopic Analysis and Multivariate Data Analysis}

A representative $600 \mathrm{MHz} 1 \mathrm{H}-\mathrm{NMR}$ spectrum of a quality control (QC) earthworm sample can be seen in Figure S2. NMR data sets for metalaxyl-exposed earthworms were first analyzed via PCA to determine global changes in metabolites. Being an unsupervised multivariate data analysis technique, PCA is frequently used to envision grouping trends and data outliers. Figure $1 \mathrm{~A}$, Figure 2A, and Figure 3A show the principal components PC1, PC2, and PC3; these reveal significant differences between treated and control groups at all three concentrations. This indicates a substantial perturbation of the earthworm metabolome after seven days' exposure to metalaxyl and metalaxyl-M. In addition, at all three concentrations $(0.5,5.0$ and $50 \mathrm{mg} / \mathrm{kg})$ the alterations in metabolome induced by metalaxyl and metalaxyl-M were clearly different, indicating an enantiospecific effect. Moreover, the metabolome change ascribed to three separate fungicide concentrations also varied, as observed when the earthworm treated with Metalaxyl-M at three concentrations were clearly separated on 3D-PCA (Figure S3).

PLS-DA was applied to the NMR data to identify the metabolites responsible for the differences seen in the PCA analysis. As seen in Figures 1B, 2B and 3B, respectively, PLS-DA plots for the treated and the control groups were clearly different. Moreover, the plots for the metalaxyl- and metalaxyl-M-treated groups were also clearly different, which once again indicated an enantiospecific effect. To determine which metabolites were affected by the two fungicides, PLS-DA analysis was used to compare treated groups with the control group. Each independent variable has a key parameter derived from the PLS-DA mode, called the variable importance in the project (VIP) value, which, when high, holds greater relevance is in classification. Thus, each peak's VIP value was determined to discern its role in the classification. 

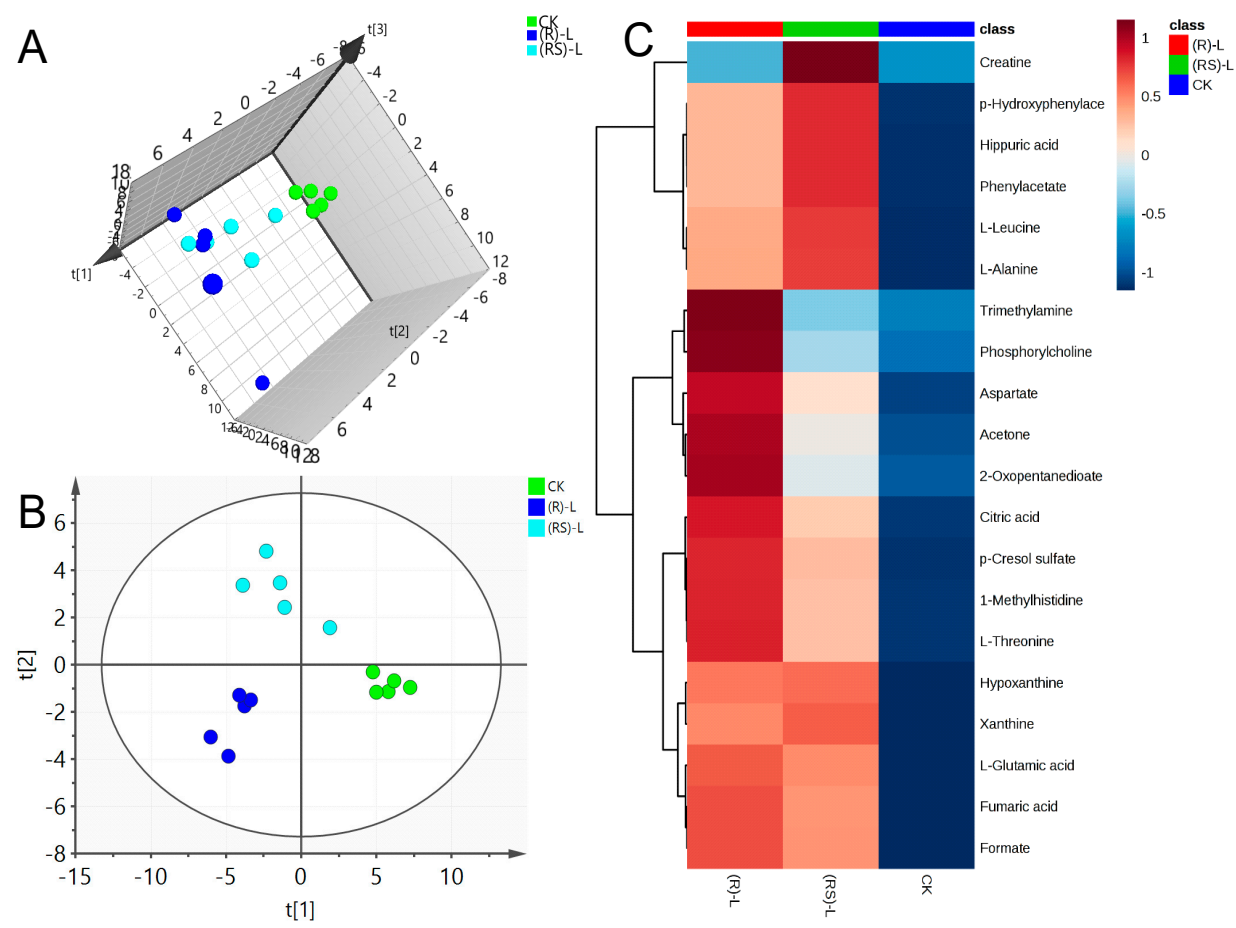

Figure 1. (A) Plots for the principal component analysis (PCA) score, (B) Plots for the partial least squares-discriminant analysis (PLS-DA) score and (C) heat map of earthworm metabolites after exposure to low $(0.5 \mathrm{mg} / \mathrm{kg})$ concentration of metalaxyl or metalaxyl-M. (RS)-L: $0.5 \mathrm{mg} / \mathrm{kg}$ Metalaxyl, (R)-L: $0.5 \mathrm{mg} / \mathrm{kg}$ Metalaxyl-M.

A
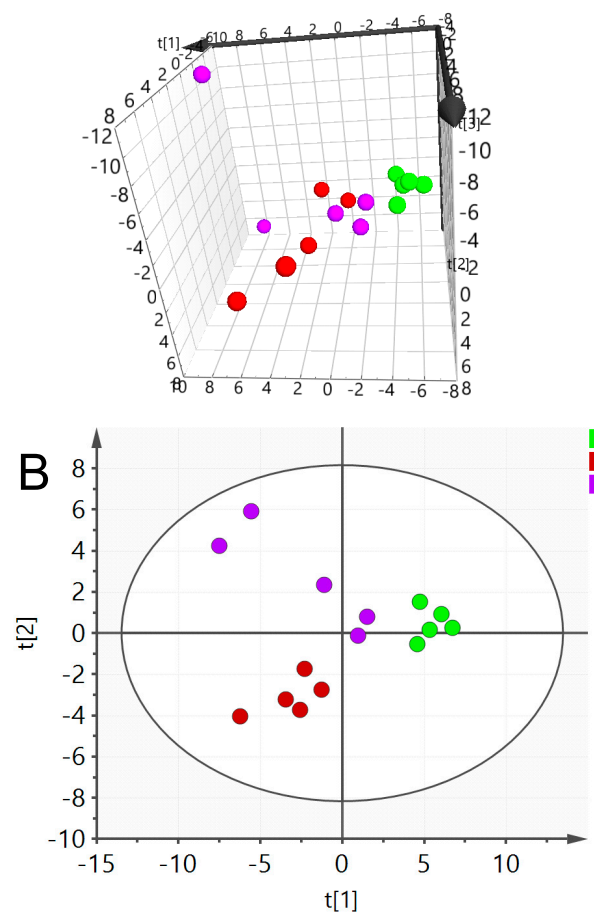

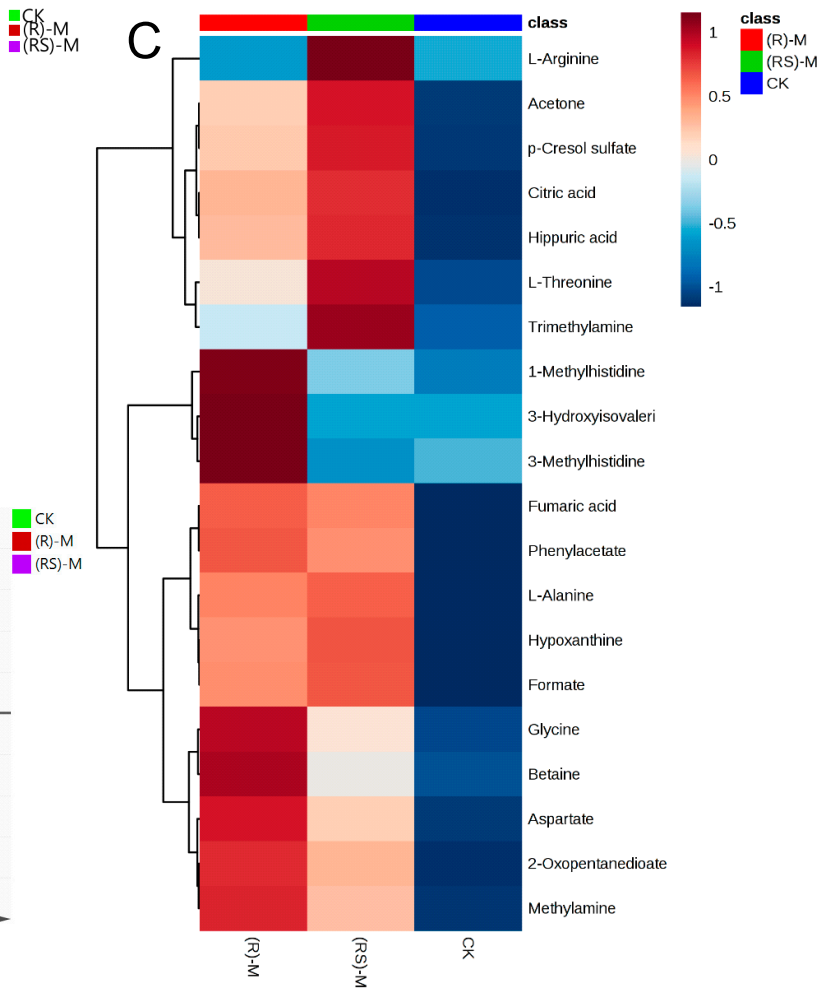

Figure 2. (A) Plots for PCA score, (B) Plots for PLS-DA score and (C) heat map of earthworm metabolites after exposure to medium $(5.0 \mathrm{mg} / \mathrm{kg}$ ) concentration of metalaxyl or metalaxyl-M. (RS)-M: $5.0 \mathrm{mg} / \mathrm{kg}$ Metalaxyl, (R)-M: $5.0 \mathrm{mg} / \mathrm{kg}$ Metalaxyl-M. 
A
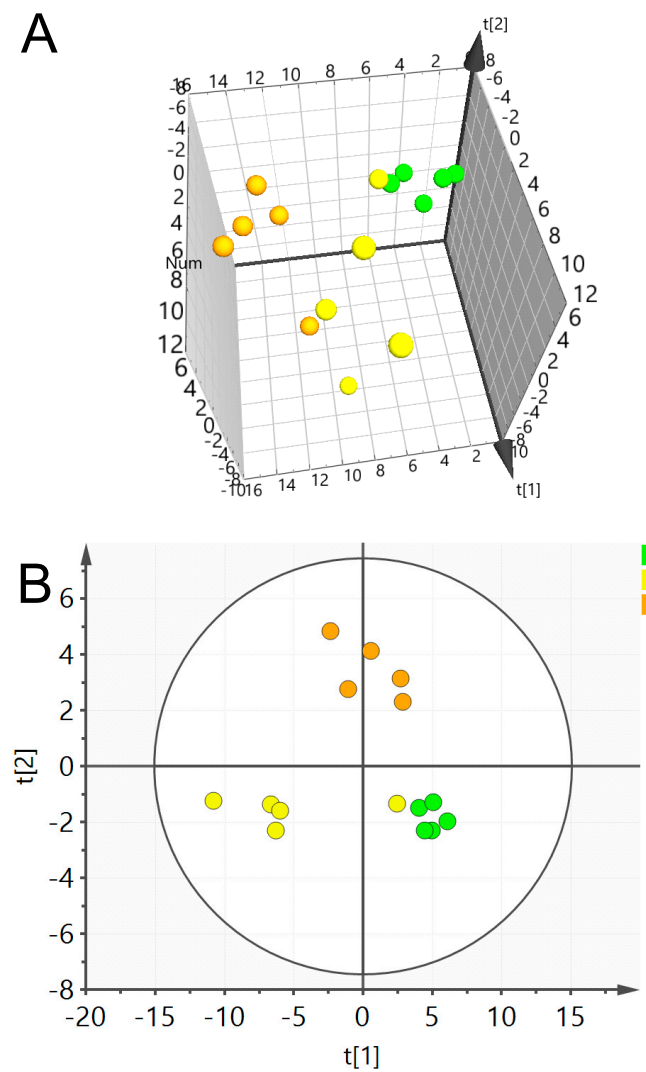

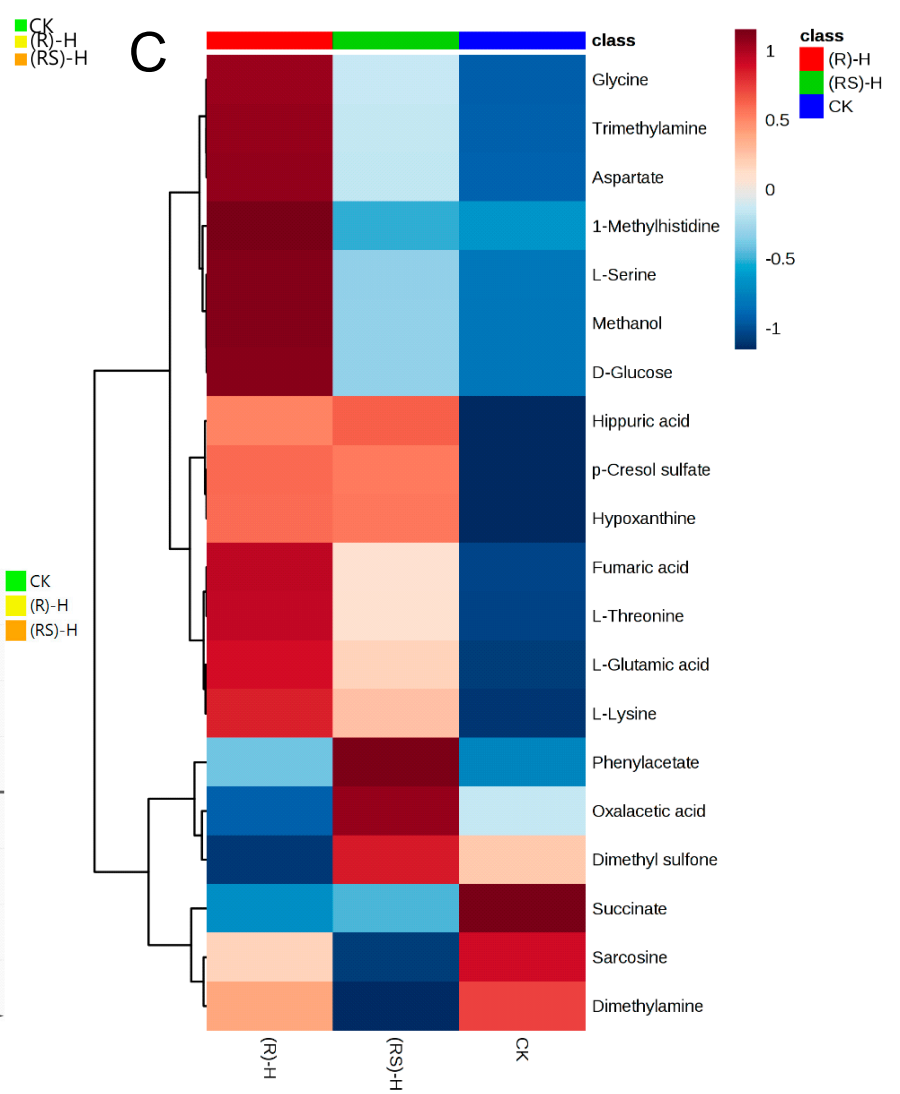

Figure 3. (A) Plots for PCA score, (B) Plots for PLS-DA score and (C) heat map of earthworm metabolites after exposure to high $(50 \mathrm{mg} / \mathrm{kg}$ ) concentration of metalaxyl or metalaxyl-M. (RS)-H: $50 \mathrm{mg} / \mathrm{kg}$ Metalaxyl, (R)-H: 50 mg/kg Metalaxyl-M.

\subsection{The Changed Metabolites}

A total of 51 metabolites whose concentrations were changed by fungicide exposure were finally identified on the basis of Student's $t$-test $(p<0.1)$ and VIP threshold (VIP $>1)$. The metabolites whose levels were notably altered were carbohydrates, amino acids, phospholipids, nucleotides, fatty acids, indoles, and so on. The groups treated with metalaxyl- and metalaxyl-M at a low concentration $(0.5 \mathrm{mg} / \mathrm{kg})$ showed changes in 39 and 33 endogenous metabolites, respectively. Groups treated at a medium concentration $(5.0 \mathrm{mg} / \mathrm{kg}$ ) showed changes in 38 and 35 endogenous metabolites, respectively, while groups treated at a high concentration $(50 \mathrm{mg} / \mathrm{kg}$ ) showed changes in 35 and 33 endogenous metabolites, respectively. These results indicate that metalaxyl-M and metalaxyl have enantiospecific effects on the metabolome. In addition, metabolites like aspartate and arginine-two key metabolites in urea cycle-were altered after $5 \mathrm{mg} / \mathrm{kg}$ metalaxyl-M and metalaxyl exposure (Figure 4).

OPLS-DA (orthogonal partial least squares- discriminant analysis) was also used as a multivariate data analysis method; it revealed clear differences in the effects of metalaxyl and metalaxyl-M at all three concentrations tested (Figure S4). 
L-Arginine

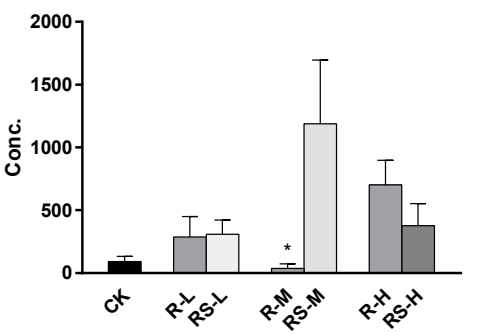

Urea

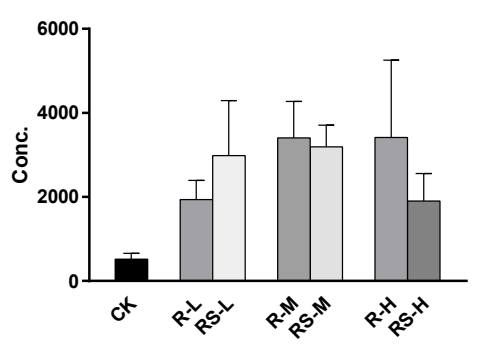

L-Asparagine

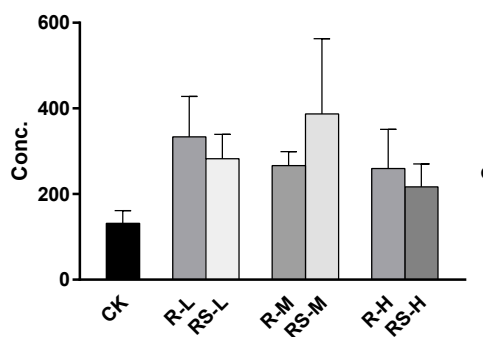

Aspartate

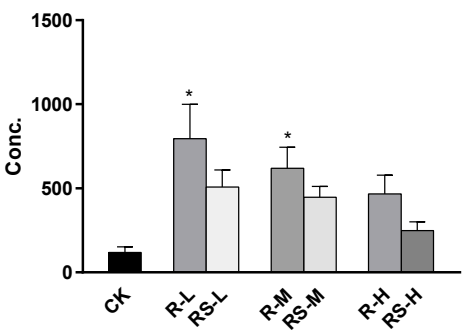

Fumaric acid

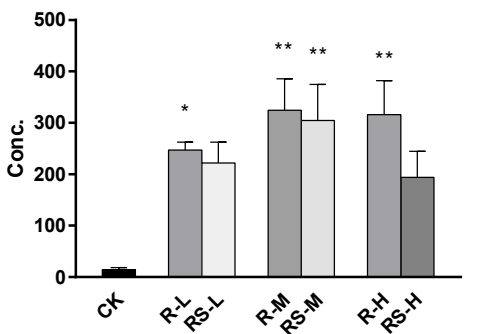

L-Alanine

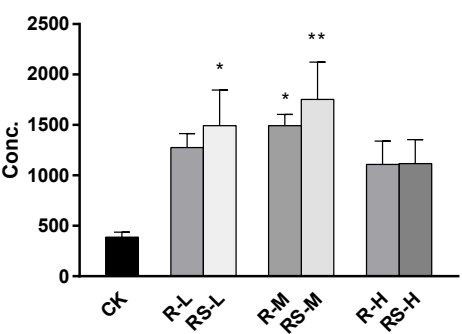

L-Glutamic acid

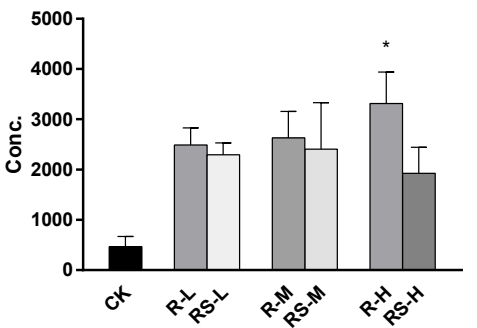

Citric acid

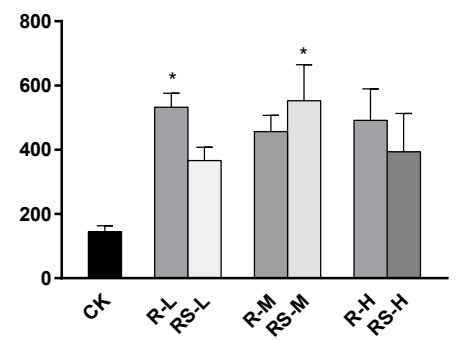

Tryptophan

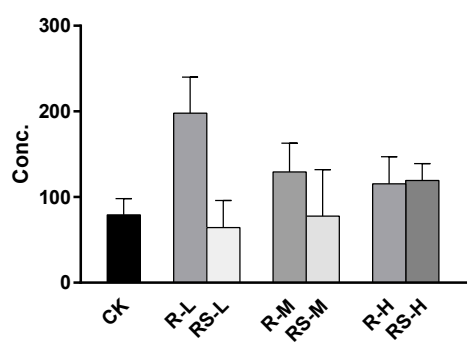

Figure 4. The concentration shifts of some metabolites after exposure to metalaxyl and metalaxyl-M. RS-L: 0.5 mg/kg Metalaxyl, R-L: 0.5 mg/kg Metalaxyl-M. RS-M: 5.0 mg/kg Metalaxyl, R-M: 5.0 mg/kg Metalaxyl-M. RS-H: 50 mg/kg Metalaxyl, R-H: 50 mg/kg Metalaxyl-M.

\subsection{Changes in the TCA and Urea Cycles}

Noteworthy changes were observed in levels of the tricarboxylic acid (TCA) and urea cycle intermediates (Figure 4). Levels of aspartate and arginine were significantly changed after exposure (Figure 5). Moreover, the $5.0 \mathrm{mg} / \mathrm{kg}$ metalaxyl-treated group had a higher concentration of arginine than that in the metalaxyl-M group. Arginine is a precursor for the synthesis of nitric oxide (NO) and plays key roles in several biological processes such as wound healing, cell division, the release of hormones, ammonia excretion, and in the immune system. The ratios of aspartate to arginine showed that the conversion of aspartate to arginine was inhibited at low concentrations of metalaxyl. The aspartate-to-arginine ratio for the metalaxyl-M-treated groups was lower than that for the metalaxyl-treated groups at all three concentrations. At low concentrations, metalaxyl-M was seen to have a greater impact on the urea cycle than metalaxyl, as shown in Figure S5.

Our studies indicate that racemic metalaxyl and R-enantiomeric metalaxyl-M had different impacts on earthworms: Specifically, metalaxyl-M up-regulated the activity of the urea cycle. 


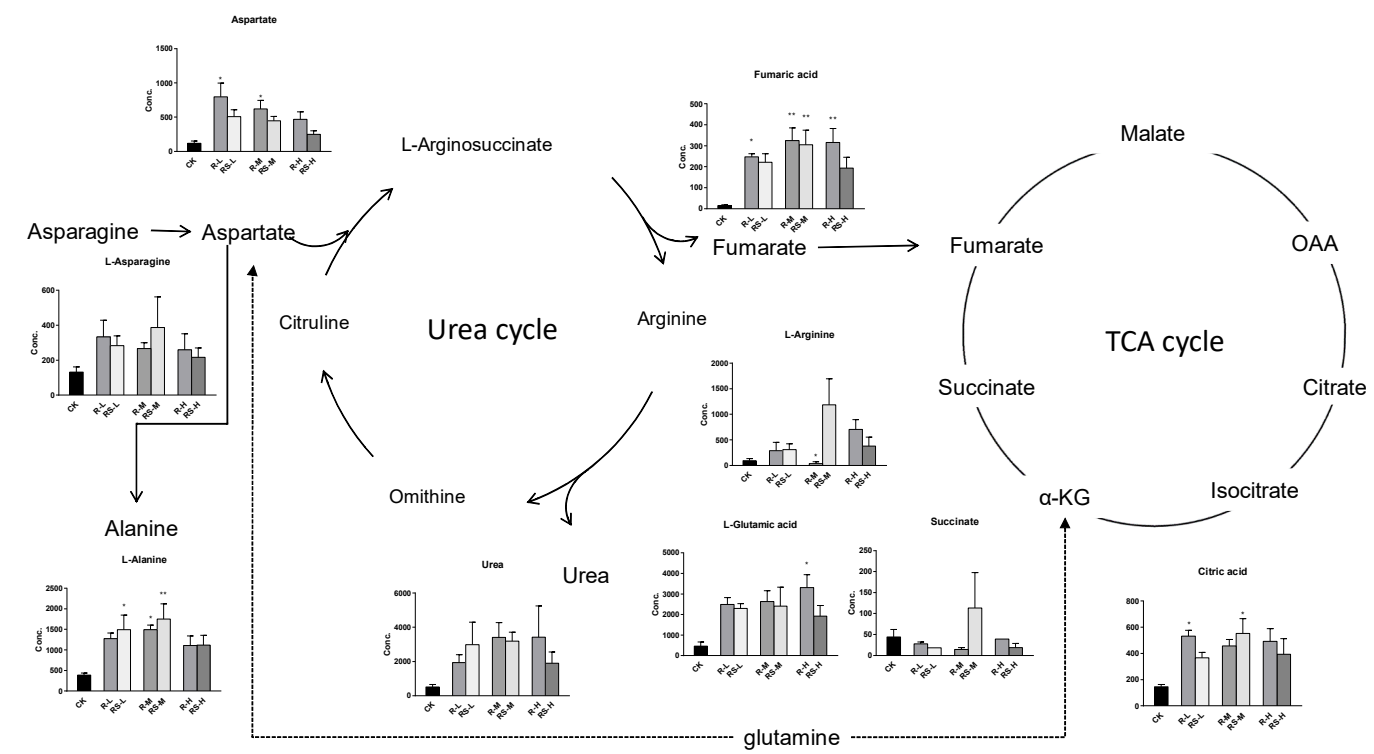

Figure 5. Disturbance of the urea and tricarboxylic acid (TCA) cycle metabolic pathway after metalaxyl and metalaxyl-M treatment.

\section{Materials and Methods}

\subsection{Soil Spiking}

E. fetida were provided by the San Huan Worm Factory (Beijing, China.). The earthworms were raised in OECD (Organisation for Economic Co-operation and Development) artificial soil, containing $67 \%$ moisture at roughly $25^{\circ} \mathrm{C}$. The earthworms were maintained in these conditions for several months before their use in metabolomic experiments, in order to minimize the effects of other environmental factors and diet. Metalaxyl (race-metalaxyl) and metalaxyl-M (r-metalaxyl) standards, both of purity $\geq 98.0 \%$ were provided by the Institute for Control of Agrochemicals, China Ministry of Agriculture (Beijing, China).

The earthworm acute toxicity test protocol described by OECD (1984) was followed to prepare the artificial soil, using 10\% peat moss (Pindstrup Mosebrug, Ryomgaard, Denmark), 20\% kaolin clay and $70 \%$ sand. The artificial soil (100 g, dry weight) was then placed in each of seven jars of clear glass and $4 \mathrm{~L}$ capacity. Ten $\mathrm{mL}$ of metalaxyl or metalaxyl-M were prepared at three separate concentrations (50, 500 and $5000 \mathrm{mg} / \mathrm{L}$ ) in HPLC grade acetone (Fisher Scientific, Waltham, MA, USA) and used for spiking the six jars. The last glass jar was spiked with only $10 \mathrm{~mL}$ of acetone for use as the unexposed control. All the acetone was allowed to evaporate by placing jars for $24 \mathrm{~h}$ in the fume hood. Then $900 \mathrm{~g}$ of soil was added to each of the jars with spiked soil and mixed thoroughly to achieve a total concentration of $0.5,5.0$ and $50.0 \mathrm{mg} / \mathrm{kg}$ (dry weight) of metalaxyl or metalaxyl-M for the pesticide-exposure experiments. Based on the OECD guidelines (1984) deionized water was used to adjust all the soils to $35 \%$ moisture content of soil dry weight (OECD, 1984).

\subsection{Metalaxyl Exposure and Tissue Extraction}

Ten mature earthworms with a mean weight of $0.45 \pm 0.05 \mathrm{~g}$ and a visible clitellum were added to the jars containing each of the seven total types of treated or control soil. No significant difference was observed in the average mass of worms used for the metalaxyl, metalaxyl-M and control groups prior to exposure. In accordance with OECD soil exposure test guidelines, earthworms were maintained in jars at $21^{\circ} \mathrm{C}$ for 7 days in natural light. They were then removed, kept on moisturized filter paper, and depurated to remove any surplus soil in their gut. After depuration for $48 \mathrm{~h}$, liquid nitrogen was used to flash freeze the earthworms, which were lyophilized and kept at $-20{ }^{\circ} \mathrm{C}$ until they were used 
for the preparation of NMR the samples. Five replicates for the control and for each of the six test groups of exposed worms were used.

For metabolomic studies, the tissue samples of the lyophilized earthworm were put into $2 \mathrm{~mL}$ centrifuge tubes. The tubes were then homogenized using the MM 400 Mixer Mills (Retsch, Haan, Germany) with one stainless-steel ball ( $5 \mathrm{~mm}$ wide) in each tube. The extraction of homogenized earthworm tissue was done in $1.2 \mathrm{~mL}$ of $0.2 \mathrm{M}$ PBS, in which, the internal calibrant was $10 \mathrm{mg} / \mathrm{L}$ of $97 \%$ pure 2,2-dimethyl-2-silapentane-5-sulfonate sodium salt (DSS; Sigma Aldrich, St. Louis, MO, USA). The buffer was prepared in 99\% pure D2O from Cambridge Isotope Laboratories (Tewksbury, MA, USA). To enable the extraction, the sample was vigorously mixed using a vortex for $30 \mathrm{~s}$, sonicated for $15 \mathrm{~min}$, and then centrifuged for $20 \mathrm{~min}$ at $14,000 \mathrm{rpm}(21,000 \times \mathrm{g})$ and $4{ }^{\circ} \mathrm{C}$. The supernatant was isolated and shifted into a fresh centrifuge tube of $1.5 \mathrm{~mL}$ capacity. This was replicated two times to eliminate any particle suspension. Finally, the ${ }^{1} \mathrm{H}-\mathrm{NMR}$ analysis was done by transferring the resulting supernatant into NMR tubes supplied by Norell of $5 \mathrm{~mm}$ capacity. From each of all the 35 samples, $40 \mu \mathrm{L}$ was taken and pooled them as a QC sample.

\subsection{H NMR Spectroscopy}

An AVANCEIII600 spectrometer (BRUKER, Billerica, MA, USA) was used to record the NMR spectra of the samples at $600 \mathrm{MHz}$ and $298 \mathrm{~K}$. A 1D NOESY pulse sequence with $20 \mathrm{ppm}$ spectral width was used to acquire all $1 \mathrm{D}^{1} \mathrm{H}-\mathrm{NMR}$ spectra. In the relaxation delay period, the resonance of water was preferentially presaturated. For each spectrum, a $4 \mathrm{~s}$ relaxation delay, $2.66 \mathrm{~s}$ acquisition time, and $0.01 \mathrm{~s}$ mixing time were used to collect 128 transient scans in $64 \mathrm{~K}$ data points. Then, using $0.3 \mathrm{~Hz}$ line broadening and zero filling to $128 \mathrm{k}$ points, the spectra were automatically Fourier transformed.

All the spectra were processed using the following method. The baseline and phases were manually corrected using MestReNova (version 9.0.1., Mestrelab, Santiago, Spain). The spectral region $\delta 0.5-9.0$ was segmented over a series of $0.04 \mathrm{ppm}$ integral regions. The region near the water resonance $(\delta 6.1-4.7)$ was excluded.

Metabolites were identified using the online Human Metabolome Database (HMDB). The biological pathway analysis was based on the Kyoto Encyclopedia of Genes and Genomes (KEGG) pathway database.

\subsection{Statistical Analysis}

The software package SIMCA-P V11.0 (Umetrics, Umeå, Sweden) was used for multivariate data analysis. To generate a group clustering overview and to search for potential outliers, PCA was carried out on the ${ }^{1} \mathrm{H}-\mathrm{NMR}$ datasets. The metabolites that altered significantly on ${ }^{1} \mathrm{H}-\mathrm{NMR}$ datasets driven group clustering were explored by the PLS-DA. A Student's $t$-test was used to discern the dissimilarities in the metabolomes of metalaxyl- and metalaxyl-M-treated earthworms and the control samples. A Student's $t$-test was applied to identify the altered metabolites $(p<0.05$ and VIP score $>1.0)$

\section{Conclusions}

Metalaxyl and metalaxyl-M were not significantly toxic to earthworms. Few metabolic processes, which might provide the basis for more targeted investigation, were found to be disrupted by metalaxyl exposure. Metalaxyl and metalaxyl-M have different enantiospecific effects and produced different disturbances in the earthworms' metabolism, particularly in the TCA and urea cycles.

The aspartate levels in the $5 \mathrm{mg} / \mathrm{kg}$ metalaxyl-M-treated group were higher than those in the equivalent metalaxyl-treated group. Arginine, one of the downstream metabolites of aspartate in the urea cycle, was seen to have a lower concentration in the $5 \mathrm{mg} / \mathrm{kg}$ metalaxyl-M-treated group as compared to the $5 \mathrm{mg} / \mathrm{kg}$ metalaxyl-treated group. This implies that metalaxyl has a stronger impact on the urea cycle. The urea cycle is involved in detoxification, and this may be why metalaxyl-M is less toxic to earthworms than metalaxyl [1]. Even as metalaxyl is replaced by metalaxyl-M in many countries, racemic metalaxyl is still one of the most widely used fungicides in the world. 
Based on this study, the S-enantiomer of metalaxyl should be subjected to further metabolomic and toxicological study.

Supplementary Materials: The following are available online, Figure S1: Body weight of earthworms before and after exposure, Figure S2: NMR spectrum from quality control group. a leucine, b valine, c 3-hydoxybutyrate, $\mathrm{d}$ methylmalonate, e lactate, $\mathrm{f}$ alanine, $g$ acetate, $\mathrm{h}$ succinate, $\mathrm{i}$ citrate, $\mathrm{j}$ trimethylamine, $\mathrm{k}$ creatine, 1 taurine, $\mathrm{m}$ glycine, $\mathrm{n}$ phenylalanine, Figure S3: PCA of metalaxyl and metalaxyl-M at three concentration levels, Figure S4: OPLS-DA (orthogonal partial least squares- discriminant analysis) of metalaxyl and metalaxyl-M at three concentration levels, Figure S5: Disturbance of arginine biosynthesis metabolic pathway after metalaxyl and metalaxyl-M treatment. and Table S1: The fold changes and VIPs of some metabolites after metalaxyl and metalaxyl-M exposed title.

Author Contributions: Z.Z. supervised the study. R.Z. designed the experiments, performed experiments, analyzed results and wrote the manuscript.

Funding: This research was funded by [National Key Research and Development Program of China] grant number [2016YFD0200202].

Acknowledgments: We gratefully acknowledge the financial support from National Key Research and Development Program of China (2016YFD0200202), and the Young Elite Scientists Sponsorship Program by CAST.

Conflicts of Interest: The authors declare no conflict of interest.

\section{References}

1. Xu, P.; Diao, J.; Liu, D.; Zhou, Z. Enantioselective bioaccumulation and toxic effects of metalaxyl in earthworm Eisenia foetida. Chemosphere 2011, 83, 1074-1079. [CrossRef] [PubMed]

2. Buser, H.-R.; Müller, M.D.; Poiger, T.; Balmer, M.E. Environmental Behavior of the Chiral Acetamide Pesticide Metalaxyl: Enantioselective Degradation and Chiral Stability in Soil. Environ. Sci. Technol. 2002, 36, 221-226. [CrossRef] [PubMed]

3. Gu, J.; Ji, C.; Yue, S.; Shu, D.; Su, F.; Zhang, Y.; Xie, Y.; Zhang, Y.; Liu, W.; Zhao, M. Enantioselective Effects of Metalaxyl Enantiomers in Adolescent Rat Metabolic Profiles Using NMR-Based Metabolomics. Environ. Sci. Technol. 2018, 52, 5438-5447. [CrossRef] [PubMed]

4. Wang, X.; Qiu, J.; Xu, P.; Zhang, P.; Wang, Y.; Zhou, Z.; Zhu, W. Rapid metabolite discovery, identification, and accurate comparison of the stereoselective metabolism of metalaxyl in rat hepatic microsomes. J. Agric. Food Chem. 2015, 63, 754-760. [CrossRef] [PubMed]

5. Zhang, P.; Zhu, W.; Wang, D.; Yan, J.; Wang, Y.; He, L. Enantioselective Effects of Metalaxyl Enantiomers on Breast Cancer Cells Metabolic Profiling Using HPLC-QTOF-Based Metabolomics. Int. J. Mol. Sci. 2017, 18, 142. [CrossRef]

6. Mosleh, Y.Y.; Ismail, S.M.; Ahmed, M.T.; Ahmed, Y.M. Comparative toxicity and biochemical responses of certain pesticides to the mature earthworm Aporrectodea caliginosa under laboratory conditions. Environ. Toxicol. 2003, 18, 338-346. [CrossRef] [PubMed]

7. Brown, J.N.; Samuelsson, L.; Bernardi, G.; Gooneratne, R.; Larsson, D.G. Aqueous and lipid nuclear magnetic resonance metabolomic profiles of the earthworm Aporrectodea caliginosa show potential as an indicator species for environmental metabolomics. Environ. Toxicol. Chem. 2014, 33, 2313-2322. [CrossRef] [PubMed]

8. Brown, S.A.E.; Simpson, A.J.; Simpson, M.J. 1H NMR metabolomics of earthworm responses to sub-lethal PAH exposure. Environ. Chem. 2009, 6, 432-440. [CrossRef]

9. Chen, Y.; Zang, L.; Shen, G.; Liu, M.; Du, W.; Fei, J.; Yang, L.; Chen, L.; Wang, X.; Liu, W.; et al. Resolution of the Ongoing Challenge of Estimating Nonpoint Source Neonicotinoid Pollution in the Yangtze River Basin Using a Modified Mass Balance Approach. Environ. Sci. Technol. 2019, 53, 2539-2548. [CrossRef]

10. Cappello, T.; Pereira, P.; Maisano, M.; Mauceri, A.; Pacheco, M.; Fasulo, S. Advances in understanding the mechanisms of mercury toxicity in wild golden grey mullet (Liza aurata) by H-1 NMR-based metabolomics. Environ. Pollut. 2016, 219, 139-148. [CrossRef]

11. Cappello, T.; Vitale, V.; Oliva, S.; Villari, V.; Mauceri, A.; Fasulo, S.; Maisano, M. Alteration of neurotransmission and skeletogenesis in sea urchin Arbacia lixula embryos exposed to copper oxide nanoparticles. Comp. Biochem. Physiol. C Toxicol. Pharmacol. 2017, 199, 20-27. [CrossRef] [PubMed] 
12. Cappello, T.; Fernandes, D.; Maisano, M.; Casano, A.; Bonastre, M.; Bebianno, M.J.; Mauceri, A.; Fasulo, S.; Porte, C. Sex steroids and metabolic responses in mussels Mytilus galloprovincialis exposed to drospirenone. Ecotoxicol. Environ. Saf. 2017, 143, 166-172. [CrossRef] [PubMed]

13. Griffith, C.M.; Williams, P.B.; Tinoco, L.W.; Dinges, M.M.; Wang, Y.; Larive, C.K. (1)H NMR Metabolic Profiling of Earthworm (Eisenia fetida) Coelomic Fluid, Coelomocytes, and Tissue: Identification of a New Metabolite-Malylglutamate. J. Proteome Res. 2017, 16, 3407-3418. [CrossRef] [PubMed]

14. Lankadurai, B.P.; Furdui, V.I.; Reiner, E.J.; Simpson, A.J.; Simpson, M.J. 1H NMR-Based Metabolomic Analysis of Sub-Lethal Perfluorooctane Sulfonate Exposure to the Earthworm, Eisenia fetida, in Soil. Metabolites 2013, 3, 718-740. [CrossRef] [PubMed]

15. McKelvie, J.R.; Yuk, J.; Xu, Y.; Simpson, A.J.; Simpson, M.J. 1H NMR and GC/MS metabolomics of earthworm responses to sub-lethal DDT and endosulfan exposure. Metabolomics 2008, 5, 84-94. [CrossRef]

16. Whitfield Aslund, M.L.; Simpson, A.J.; Simpson, M.J. 1H NMR metabolomics of earthworm responses to polychlorinated biphenyl (PCB) exposure in soil. Ecotoxicology 2011, 20, 836-846. [CrossRef]

17. Yuk, J.; Simpson, M.J.; Simpson, A.J. 1-D and 2-D NMR-based metabolomics of earthworms exposed to endosulfan and endosulfan sulfate in soil. Environ. Pollut. 2013, 175, 35-44. [CrossRef]

18. Whitfield Aslund, M.L.; McShane, H.; Simpson, M.J.; Simpson, A.J.; Whalen, J.K.; Hendershot, W.H.; Sunahara, G.I. Earthworm sublethal responses to titanium dioxide nanomaterial in soil detected by (1)H NMR metabolomics. Environ. Sci. Technol. 2012, 46, 1111-1118. [CrossRef]

19. Vignet, C.; Cappello, T.; Fu, Q.; Lajoie, K.; De Marco, G.; Clérandeau, C.; Mottaz, H.; Maisano, M.; Hollender, J.; Schirmer, K.; et al. Imidacloprid induces adverse effects on fish early life stages that are more severe in Japanese medaka (Oryzias latipes) than in zebrafish (Danio rerio). Chemosphere 2019, 225, 470-478. [CrossRef]

20. Cappello, T.; Giannetto, A.; Parrino, V.; De Marco, G.; Mauceri, A.; Maisano, M. Food safety using NMR-based metabolomics: Assessment of the Atlantic bluefin tuna, Thunnus thynnus, from the Mediterranean Sea. Food Chem. Toxicol. 2018, 115, 391-397. [CrossRef]

21. Rochfort, S.J.; Ezernieks, V.; Yen, A.L. NMR-based metabolomics using earthworms as potential indicators for soil health. Metabolomics 2008, 5, 95-107. [CrossRef]

22. Brown, S.A.; McKelvie, J.R.; Simpson, A.J.; Simpson, M.J. 1H NMR metabolomics of earthworm exposure to sub-lethal concentrations of phenanthrene in soil. Environ. Pollut. 2010, 158, 2117-2123. [CrossRef] [PubMed]

23. Chen, T.; Liu, Y.; Li, M.-H.; Xu, H.-D.; Sheng, J.-Y.; Zhang, L.; Wang, J.-S. Integrated 1H NMR-based metabolomics analysis of earthworm responses to sub-lethal $\mathrm{Pb}$ exposure. Environ. Chem. 2016, $13,792$. [CrossRef]

24. Wang, L.; Huang, X.; Laserna, A.K.; Li, S.F. ${ }^{1} \mathrm{H}$ nuclear magnetic resonance-based metabolomics study of earthworm Perionyx excavatus in vermifiltration process. Bioresour. Technol. 2016, 218, 1115-1122. [CrossRef]

25. Tang, R.; Ding, C.; Ma, Y.; Wang, J.; Zhang, T.; Wang, X. Time-dependent responses of earthworms to soil contaminated with low levels of lead as detected using ${ }^{1} \mathrm{H}$ NMR metabolomics. RSC Adv. 2017, 7, 34170-34181. [CrossRef]

26. Yuk, J.; Simpson, M.J.; Simpson, A.J. 1-D and 2-D NMR metabolomics of earthworm responses to sub-lethal trifluralin and endosulfan exposure. Environ. Chem. 2011, 8, 281-294. [CrossRef]

27. Yuk, J.; Simpson, M.J.; Simpson, A.J. Coelomic fluid: A complimentary biological medium to assess sub-lethal endosulfan exposure using ${ }^{1} \mathrm{H}$ NMR-based earthworm metabolomics. Ecotoxicology 2012, 21, 1301-1313. [CrossRef] [PubMed]

28. Lankadurai, B.P.; Wolfe, D.M.; Whitfield Åslund, M.L.; Simpson, A.J.; Simpson, M.J. ${ }^{1}$ H NMR-based metabolomic analysis of polar and non-polar earthworm metabolites after sub-lethal exposure to phenanthrene. Metabolomics 2012, 9, 44-56. [CrossRef]

29. Baylay, A.J.; Spurgeon, D.J.; Svendsen, C.; Griffin, J.L.; Swain, S.C.; Sturzenbaum, S.R.; Jones, O.A. A metabolomics based test of independent action and concentration addition using the earthworm Lumbricus rubellus. Ecotoxicology 2012, 21, 1436-1447. [CrossRef]

30. Lankadurai, B.P.; Nagato, E.G.; Simpson, A.J.; Simpson, M.J. Analysis of Eisenia fetida earthworm responses to sub-lethal C60 nanoparticle exposure using (1)H-NMR based metabolomics. Ecotoxicol. Environ. Saf. 2015, 120, 48-58. [CrossRef] 
31. Ch, R.; Singh, A.K.; Pandey, P.; Saxena, P.N.; Reddy Mudiam, M.K. Identifying the metabolic perturbations in earthworm induced by cypermethrin using gas chromatography-mass spectrometry based metabolomics. Sci. Rep. 2015, 5, 15674. [CrossRef] [PubMed]

32. Duan, X.; Fu, X.; Song, J.; Li, H.; Sun, M.; Hu, F.; Xu, L.; Jiao, J. Physiological and molecular responses of the earthworm Eisenia fetida to polychlorinated biphenyl contamination in soil. Environ. Sci. Pollut. Res. Int. 2017, 24, 18096-18105. [CrossRef] [PubMed]

33. Gillis, J.D.; Price, G.W.; Prasher, S. Lethal and sub-lethal effects of triclosan toxicity to the earthworm Eisenia fetida assessed through GC-MS metabolomics. J. Hazard. Mater. 2017, 323, 203-211. [CrossRef] [PubMed]

34. Jones, O.A.; Spurgeon, D.J.; Svendsen, C.; Griffin, J.L. A metabolomics based approach to assessing the toxicity of the polyaromatic hydrocarbon pyrene to the earthworm Lumbricus rubellus. Chemosphere 2008, 71, 601-609. [CrossRef] [PubMed]

35. McKelvie, J.R.; Whitfield Aslund, M.; Celejewski, M.A.; Simpson, A.J.; Simpson, M.J. Reduction in the earthworm metabolomic response after phenanthrene exposure in soils with high soil organic carbon content. Environ. Pollut. 2013, 175, 75-81. [CrossRef]

36. Simpson, M.J.; McKelvie, J.R. Environmental metabolomics: New insights into earthworm ecotoxicity and contaminant bioavailability in soil. Anal. Bioanal. Chem. 2009, 394, 137-149. [CrossRef]

37. Whitfield Aslund, M.; Stephenson, G.L.; Simpson, A.J.; Simpson, M.J. Comparison of earthworm responses to petroleum hydrocarbon exposure in aged field contaminated soil using traditional ecotoxicity endpoints and 1H NMR-based metabolomics. Environ. Pollut. 2013, 182, 263-268. [CrossRef]

Sample Availability: Samples of the compounds are available from the authors.

(C) 2019 by the authors. Licensee MDPI, Basel, Switzerland. This article is an open access article distributed under the terms and conditions of the Creative Commons Attribution (CC BY) license (http:// creativecommons.org/licenses/by/4.0/). 